FACTA UNIVERSITATIS

Series: Mechanical Engineering Vol. 18, No 2, 2020, pp. 205 - 217

https://doi.org/10.22190/FUME200611025P

Original scientific paper

\title{
FINITE ELEMENT MODELING OF TEMPERATURE FIELDS ON THE CUTTING EDGE IN THE DRY HIGH-SPEED TURNING OF AISI 1045 STEEL
}

\section{Roberto Pérez ${ }^{1}$, Luis Hernández ${ }^{1}$, Ana Quesada ${ }^{1}$, Julio Pino², Enrique Zayas $^{3}$}

${ }^{1}$ CAD/CAM Study Center, Engineering Faculty, University of Holguín, Holguín, Cuba ${ }^{2}$ Civil Engineering, Faculty of Technical Sciences, Universidad Estatal del Sur de Manabí, Ecuador

${ }^{3}$ Departament of Mechanical Engineering, School of Engineering of Barcelona (ETSEIB), Universitat Politècnica de Catalunya, Barcelona, Spain

\begin{abstract}
High-speed turning is an advanced and emerging machining technique that in contrast to the conventional machining, allows the manufacture of the workpiece with high accuracy, efficiency and quality, with lower production costs and with a considerable reduction in the machining times. The cutting tools used for the conventional machining cannot be employed for high-speed machining due to a high temperature induced in machining and a lower tool life. Therefore, it is necessary to study the influence of high cutting speeds on the temperature distribution in different typologies of cutting tools, with the aim of evaluating their behavior. In this paper, a finite element method modeling approach with arbitrary Lagrangian-Eulerian fully coupled thermal-stress analysis is employed. The research presents the results of different cutting tools (two coated carbide tools and uncoated cermet) effects on average surface temperature fields on the cutting edge in the dry high-speed turning of AISI 1045 steel. The numerical experiments were designed based on different cutting tools like input parameters and different temperature field zones like dependent variables in the dry high-speed turning of AISI 1045 steel. The results indicate that the dry high-speed turning of AISI 1045 steel does not influence significantly the temperature field zones when P10, P15 or P25 inserts are used. Therefore, the use of a dry high-speed turning method, which reduces the amount of lubricant and increases productivity, may represent an alternative to turning to the extent here described.
\end{abstract}

Key Words: High-speed Turning, FEM Modeling, Temperature Fields, Tool-chip Interface Friction, Round Edge

Received June 11, 2020 / Accepted July 15, 2020

Corresponding author: Pérez, Roberto

Affiliation, address: CAD/CAM Study Center, University of Holguín, Cuba

E-mail: roberto.perez@uho.edu.cu 


\section{INTRODUCTION}

High-Speed Machining (HSM) constitutes one of the new technologies that, in contrast to the conventional machining, allows the manufacture of parts with high accuracy, efficiency and quality, with lower production costs and with a significant reduction in the machining times. Besides, the HSM offers other advantages such as excellent dimensional accuracy and a better surface finish just as it facilitates the machining of materials with high surface hardness [1].

The metal cutting process can be considered as a deformation process where the deformation is highly concentrated in a small area. Therefore, the cutting can be conducted as a chip formation process and may be simulated using the Finite Element Method (FEM). The classic orthogonal cutting model for continuous chip formation adopts continuous plane-strain deformation conditions. Primary representation of the cutting model is illustrated in Fig. 1. In the conventional machining cutting at low speeds, the friction mechanism is more effective at the tool flank face. However, in the HSM due to the considerable cutting speed, there exists an increase in the chip-tool contact friction, and it is much more significant at the tool rake face [2].

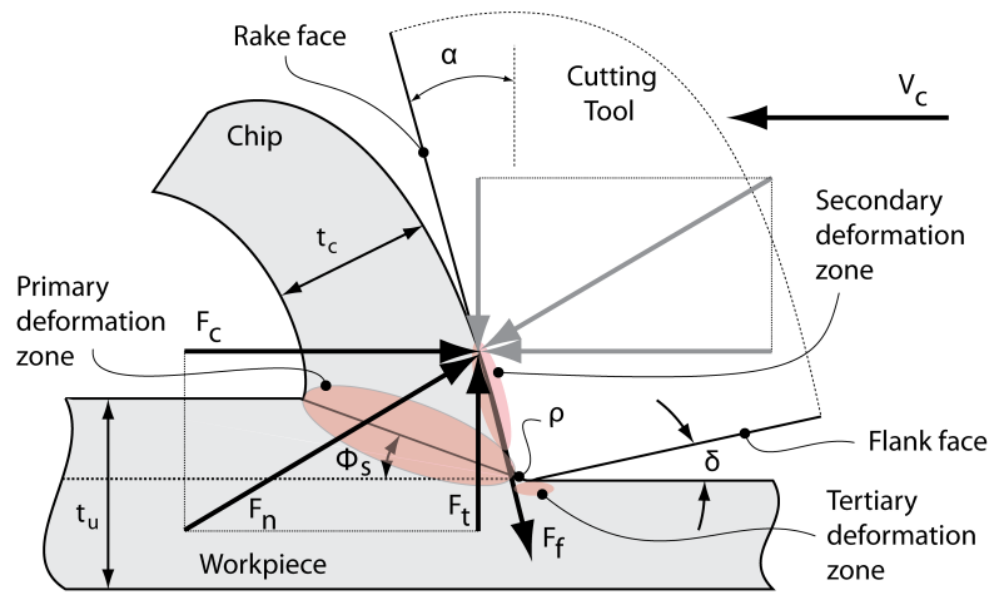

Fig. 1 Primary representation of the machining process, adapted from [2, 3]

The distribution of normal stress $\left(\sigma_{\mathrm{n}}\right)$ and shear stress $\left(\tau_{\mathrm{f}}\right)$ describe the cutting temperature and tool wear. These distributions are generally represented as expressed in Fig. 2 in dry conditions $[4,5]$. Over length $1_{\mathrm{p}}$, normal stress is very high and the metal adheres to the rake face; therefore, a plastic flow occurs in the work material. In this region, the shearing stress is independent of the normal load which is recognized as the sticking region of friction. On length $1_{s}$, smaller normal stresses occur and the typical condition of sliding friction applies, where Coulomb's friction law can be functional.

As a result of the metal cutting process, heat generation occurs in several regions or interfaces $[7,8,9]$. The primary sources of heat generation in machining are the plastic deformation of the layer machined and adjacent at the cutting surface as well as the friction that occurs between the tool and the workpiece being machined. 


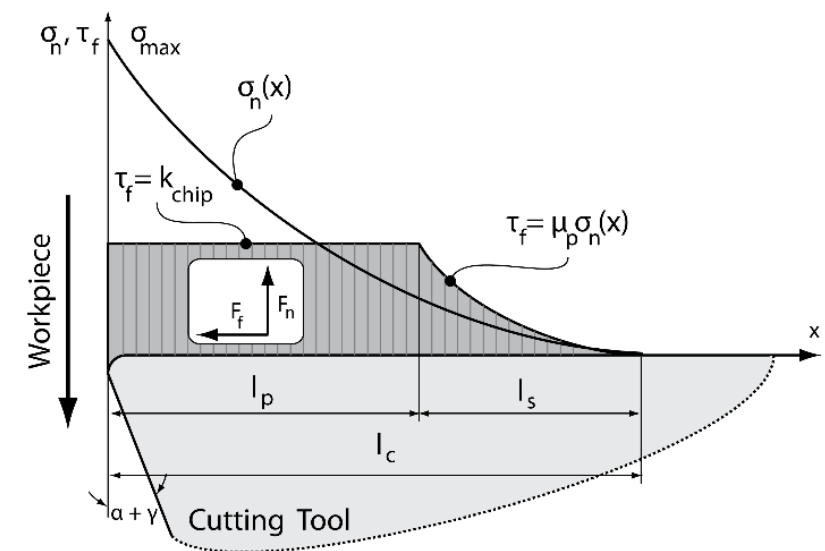

Fig. 2 Normal and frictional stress distributions on the tool rake face, adapted from [6]

Fig. 3 shows an idealized orthogonal machining process using a sharp tool. In this idealization, there are two heat sources; the primary shear plane source $\left(\mathrm{Q}_{1}\right)$ and the rake face source $\left(Q_{2}\right)$, with the thermal constriction resistance $\left(R_{1}\right.$ and $\left.R_{2}\right)$. The latter accounts for the secondary plastic deformation area in the chip, and the tool-chip friction. The inset in Fig. 1 shows that point-to-point contact is encountered in the sliding zone. The heat generated in the process comes into the tool through a limited number of small contacts [10].

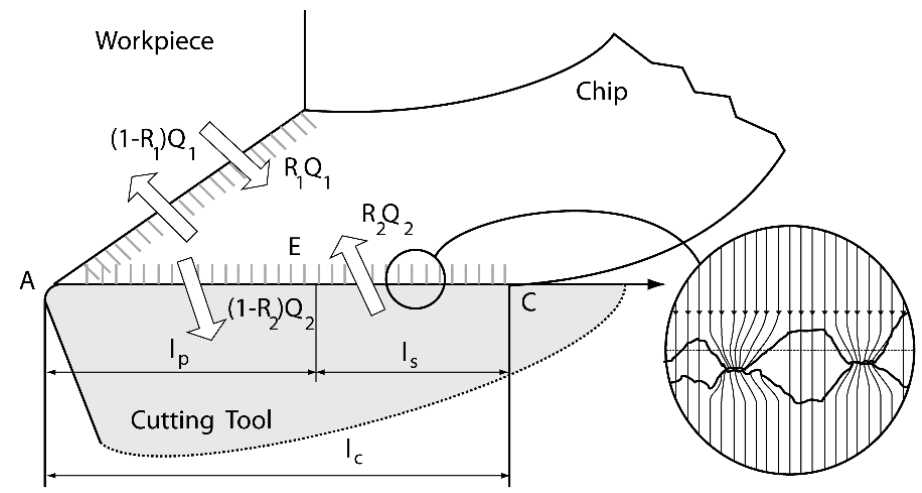

Fig. 3 Contact configuration and heat sources in the tool-chip-workpiece system, adapted from [10]

It has been perceived that 60 to 80 percentage of the heat generated in the cutting process is evacuated through the chip. The percentage increases to the same magnitude as the cutting speed does. In the technological process of turning on average it has been observed that 50 to 86 percentage of the heat is evacuated through the chip, 10 to 40 percentage moves the tool, from 3 to 9 percentage moves into the workpiece and about one percentage radiates to the environment. Heat distribution is affected by several factors, the most important of them being the cutting speed and the cut thickness of the cutting process $[7,8,9,11,12]$. 
The cutting temperature is not constant throughout the cutting tool, the chip or the workpiece. It can be observed that the maximum temperature is developed not on the very cutting edge, but at the tool rake, some distance away from the cutting edge [13].

In recent years, the quantity of research projects related to the evaluation of the useful life of cutting tools, using different cooling technologies, has increased; however, there are few studies on the operation of dry turning at high cutting speeds in carbon construction steels, used in the manufacture of machine parts, as shown below.

Authors like Özel et al. [3], Leopold [14], and Chinchanikar et al. [15] developed finite element studies for the orthogonal cutting in HSM. Continuous re-meshing and adaptive meshing are the principal tools employed for avoiding the difficulties associated with deformation-induced element distortion, and for resolving fine-scale features in the solution. The model accounts for dynamic effects, heat conduction, mesh-on-mesh contact with friction and full thermos-mechanical coupling. This primary approach did not look at the scope, the temperature distribution by specific areas of the cutting tools.

Özel and Altan [16] develop a methodology for simulating the cutting process in flat end milling operation and predicting chip flow, cutting forces, tool stresses and temperatures using FEM. As an application, machining of P-20 mold steel at $30 \mathrm{HRC}$ hardness using uncoated carbide tooling was investigated. The highest tool temperatures were predicted at the primary cutting edge of the flat end mill insert regardless of cutting conditions, using the commercially available software DEFORM-2D. These temperatures increase wear development at the primary cutting edge. However, a predictive curve analysis adjusting the temperature distribution was not performed.

Özel [17] investigates the influence of edge preparation in Cubic Boron Nitrite (CBN) cutting tools on process parameters and tool performance by utilizing FEM simulations and high-speed orthogonal cutting tests on AISI H-13 hot work steel. Distribution of temperatures in the workpiece, chip and the CBN tool was obtained from FEM simulations. The temperature generated at the chip-tool interface was found substantially higher than the other temperatures. The author does not make a predictive analysis of fitting curves for the temperature distribution by regions of the cutting tool.

In the work of Fang et al. [18] the thermal impact in cutting are considered. The effects of land length and second rake angle of the grooved tool on chip formation, cracking and temperature are discussed. Some simulation results are compared with other published analytical and experimental results.

Several authors [19-26] illustrate a dynamic explicit Arbitrary Lagrangian-Eulerian (ALE) based on FEM modeling using commercially available software's. FEM techniques such as adaptive meshing, explicit dynamics and fully coupled thermal-stress analysis are combined to simulate HSM with an orthogonal cutting model. Finite element modeling of temperature distribution induced by round edge cutting tools is performed in numerous materials. The authors do not obtain adjustment curves of the temperature distribution in every surface of the cutting tools.

A structural model of a soft/hard composite-coated textured tool was proposed by Yun et al. [27] and validated through a three-dimensional numerical simulation. Its dry turning performance as applied to AISI1045 steel was analyzed via orthogonal experiments for different coating parameters. The authors do not differentiate the analyses by heat transfer zones in the cutting tool. A similar analysis was carried out by Akbar et al. [28] on AISI / SAE 4140 steel with uncoated and TiN-coated tools. 
An improved understanding of heat partition between the tool and the chip is required to obtain more accurate finite element models of machining processes. Akbar et al. [29] performed an orthogonal cutting of AISI/SAE 4140 steel with tungsten-based cemented carbide cutting inserts at cutting speeds ranging between 100 and $628 \mathrm{~m} / \mathrm{min}$. Chip formation was simulated using a fully coupled thermo-mechanical FEM. The results show that over a wide range of cutting speeds, the accuracy of FEM output such as toolchip interface temperature, are significantly dependent on the specified value of heat partition. The analysis discretized by thermal transfer areas was not performed.

From another perspective, Heisel et al. [30] describe the procedure for creating and verifying a thermos-mechanical FEM model of orthogonal cutting. The temperature was measured in the secondary shear zone and at the exterior surface of the chip, which was analytically estimated as well and compared with the experimental values checking the proposed model. Finally, the values for temperature, among other variables are related to those calculated with the FEM cutting model. No detailed analysis of heat behavior by cutting tool zones was obtained.

The objective of the present study is to increase a better understanding of the influence of the dry high-speed turning on temperature distribution in the different zones of the cutting tools. Based on 2-D thermo-viscoplastic FEM cutting simulations, the predicted distributions of temperature within the tool coating and substrate have been investigated. Orthogonal turning FEM simulation tests with different cutting tool materials and machining conditions have been carried out in order to achieve the abovestated objective. During and after each test, several numerical parameters have been quantified to calibrate the finite element model.

\section{MATERIALS AND METHODS}

\subsection{Sample characteristics}

In the present research, the AISI 1045 carbon steel was selected as work material, in hot rolled conditions, as widely used in the manufacturing of parts for metal mechanics and the automobile industry. This steel is considered a critic standard for manufacturing machine parts. The composition of AISI 1045 steel is perlite-ferrite at 50\%, with a medium carbon percentage, which is the maximum percentage for its group, leading to improved mechanical properties at the cost of making machinability more difficult. The chemical composition and mechanical properties of AISI 1045 are given in Table 1 [31].

The microstructure and grain size were examined on the whole transversal section of the workpiece, using an optical microscope Nikon Epiphot. The grain size was $8 \mu \mathrm{m}$. The hardness of the sample was measured on the complete cross-section, using a microhardness tester Shimadzu. The average hardness was $258 \mathrm{HB}$.

\subsection{Characteristics of inserts and experimental arrangement of the research}

Two coated carbide tools (GC4215-P15 and GC4225-P25) were used during cutting tests as well as the uncoated cermet CT5015-P10, the tested tools were manufactured by SandvikCoromant. The cutting tool characteristics are given in Table 2. 
Table 1 Chemical composition of AISI 1045 steel

\begin{tabular}{cccccc}
\hline Elements & $\begin{array}{c}\text { Chemical } \\
\text { composition, } \%\end{array}$ & $\begin{array}{c}\text { Proof Strength }(0,2 \% \\
\text { Yield), Mpa }\end{array}$ & $\begin{array}{c}\text { Tensile Strength, } \\
\mathrm{MPa}\end{array}$ & $\begin{array}{c}\text { Elongation, \% } \\
\text { HRC } \\
\text { Hardness }\end{array}$ \\
\hline $\mathrm{C}$ & 0,450 & & & & \\
$\mathrm{Si}$ & 0,150 & & & & \\
$\mathrm{Mn}$ & 0,710 & 300 & 570 & & \\
$\mathrm{P}$ & 0,036 & & & & \\
$\mathrm{~S}$ & 0,007 & & & \\
$\mathrm{Cr}$ & 0,122 & & & \\
$\mathrm{Ni}$ & 0,024 & & & & \\
$\mathrm{Al}$ & 0,035 & & & & \\
\hline
\end{tabular}

Table 2 Characteristics of inserts

\begin{tabular}{|c|c|c|c|c|c|c|c|c|c|}
\hline \multirow[t]{2}{*}{ Insert } & \multicolumn{4}{|c|}{ Coatings } & \multicolumn{5}{|c|}{ Substrates } \\
\hline & $\begin{array}{l}\text { First } \\
\text { layer }\end{array}$ & $\begin{array}{l}\text { Second } \\
\text { layer }\end{array}$ & $\begin{array}{l}\text { Third } \\
\text { layer }\end{array}$ & $\begin{array}{l}\text { Width } \\
(\mu \mathrm{m})\end{array}$ & W & $\mathrm{Ti}$ & Co & $\mathrm{Nb}$ & $\mathrm{Al}_{2} \mathrm{O}_{3}$ \\
\hline CT5015-P10 & 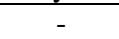 & - & - & 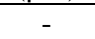 & 20,68 & 47,2 & 17,71 & 8,71 & 5,7 \\
\hline GC4215-P15 & TiN & $\mathrm{Al}_{2} \mathrm{O}_{3}$ & $\mathrm{Al}_{2} \mathrm{O}_{3}$ & 15 & 96,19 & 1,44 & 2,38 & - & - \\
\hline GC4225-P25 & $\mathrm{Ti}(\mathrm{C}, \mathrm{N})$ & $\mathrm{Al}_{2} \mathrm{O}_{3}$ & - & 10 & 94,77 & 2,1 & 3,13 & - & - \\
\hline
\end{tabular}

This research is focused on the study of the dry high-speed turning of the AISI 1045 steel, using three inserts with three levels of cutting speeds and five levels of machining times. Also, two replicas for the acquisition of information have been made (90 tests). The experiments have been conducted on ten solid cylindrical workpieces with an initial diameter of $80 \mathrm{~mm}$ and a length of $300 \mathrm{~mm}$. The depth of cut $(\mathrm{a}=0,5 \mathrm{~mm})$ and feed rate ( $\mathrm{f}=0,1 \mathrm{~mm} / \mathrm{r}$ ) were kept constant.

\subsection{Finite Element Analysis modeling}

\subsubsection{Principles of Finite Element Analysis modeling}

Two-dimensional cutting simulations were carried out to explore the effect of the dry high-speed turning in three different cutting tools, using DEFORM-2D software developed for significant plastic deformation problems. The simulation of chip flow was achieved by adaptively remeshing the workpiece nearby the tool tip.

The workpiece was modeled as rigid-plastic and the Oxley law was implemented to describe material flow as a function of strain, strain rate and temperature [3]. 1838 isoparametric quadrilateral elements were utilized for the workpiece mesh. On the other hand, the tool was modeled as rigid and meshed with 2709 elements. Materials thermal parameters were set as a function of the actual temperature, based-on software database [3].

\subsubsection{Flow stress data of the workpiece and substrate properties of the coatings}

This study considers Johnson-Cook (JC) work material models for AISI 1045 steel [6]. The JC work material model describes the flow stress of the material by considering strain, strain rate, and temperature effects as given in Eq. (1):

$$
\bar{\sigma}=\left[A+B(\bar{\varepsilon})^{n}\right]\left[1+C \ln \left(\frac{\dot{\bar{\varepsilon}}}{\dot{\bar{\varepsilon}}_{0}}\right)\right]\left[1-\left(\frac{T-T_{0}}{T_{m}-T_{0}}\right)^{m}\right]
$$


Constants $A$ (plastic equivalent strain, MPa), $B$ (strain related constant, MPa), $C$ (strain-rate sensitivity, MPa), $n$ (strain-hardening parameter), and $m$ (thermal softening parameter) of the JC constitutive model are obtained by the Split Hopkinson Pressure Bar SHPB tests conducted at strain ranges of 0,05 to 0,2 , strain-rate of $7500 \mathrm{l} / \mathrm{s}$, and temperature ranges of $35^{\circ} \mathrm{C}$ to $625^{\circ} \mathrm{C}$ for AISI 1045 steel as given in Table 3[6].

Table 3 Johnson-Cook material constants

\begin{tabular}{lcccccc}
\hline Material & $\mathrm{T}_{\mathrm{m}}\left({ }^{\circ} \mathrm{C}\right)$ & $\mathrm{A}(\mathrm{MPa})$ & $\mathrm{B}(\mathrm{MPa})$ & $\mathrm{C}$ & $\mathrm{n}$ & $\mathrm{m}$ \\
\hline AISI 1045 & 1460 & 553,1 & 600,8 & 0,0134 & 0,234 & 1 \\
\hline
\end{tabular}

Two coated carbide tools (CVD) GC4215-P15 and GC4225-P25 were compared during cutting tests as well as the uncoated cermet CT5015-P10. All the tested tools were manufactured by Sandvik and the tool holder having the designation SCLCR/L 2020K 12. After the tests, the cutting tools were analyzed using the JEOL Scanning Electron Microscope. Every cutting edge of the cutting tools was previously inspected using the NIKON EPIPHOT optical microscope [31].

The simulation considered a uniform coating thickness of $15 \mu \mathrm{m}$ on the rake face, cutting edge, and flank face for the P15 insert and $10 \mu \mathrm{m}$ for the P25 insert. The interface between the coating and the substrate was assumed to be perfectly bonded together, so that an interfacial slip during loading was neglected. The thermal properties for the workpiece material and the cutting tools were obtained from the literature. To model the thermal contact without significant resistance, a heat transfer coefficient of $45 \mathrm{~N} / \mathrm{sec} / \mathrm{C}$ was utilized. A shear friction factor of 0,6 and a mesh cutting tool of 2500 were used. The tool wear Usui model was applied.

\subsubsection{Boundary conditions}

Fig. 4 briefly shows the concept of this finite element model. To model the chip formation, the coupled Eulerian-Lagrangian finite element method was employed using the commercial software package DEFORM-2D. With this model, the chip formation is simulated similarly to a fluid flow model. The fluid in this case is the workpiece material which continuously enters the Eulerian domain at the top and then flows against the tool which is fixed in space. The software is accomplished of controlling overlock based on the boundary conditions defined for the workpiece; therefore, the nodes on the left side boundary are fixed in the $\mathrm{X}$ axis direction. At the same time, the nodes at the bottom remain fixed in the $\mathrm{Y}$ direction.

Thermal boundary conditions are defined to facilitate thermo-mechanical modeling of solutions. The leading boundary conditions are: (a) heat is generated due to the plastic deformation of the part while the tool penetrates the material, assuming that $90 \%$ of all plastic deformation work is converted to heat; (b) the heat generated is due to the friction between the tool and the chip; and (c) the workpiece emits heat to the environment.

The results will specifically check the influence of cutting speed on the twodimensional model of the dry high-speed machining of AISI 1045 steel for different cutting tools (P10, P15, P25). The overlock has been carried out in such a way that when there is a penetration of one element over another with a value greater than $0,0014 \mathrm{~mm}$, the software will perform meshing. 


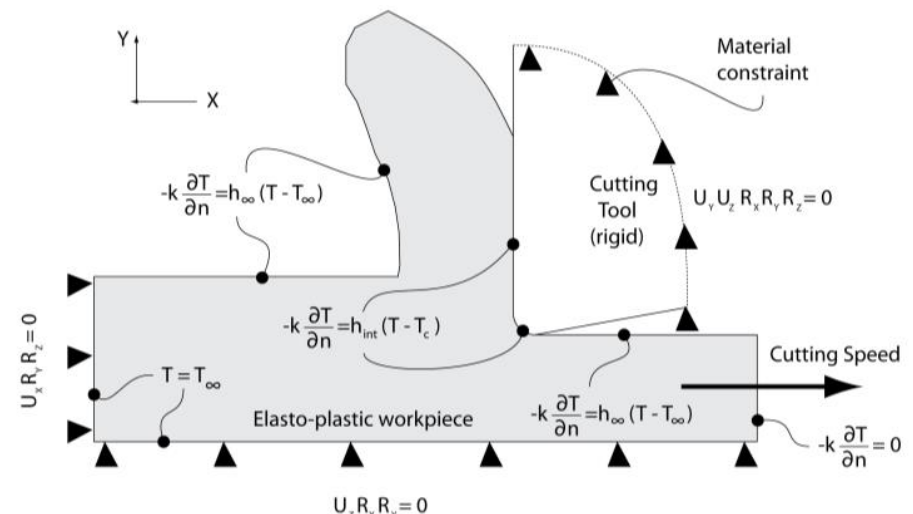

Fig. 4 Modeling of orthogonal cutting with coupled Eulerian-Lagrangian method

Table 4 shows the numerical variables considered for simulation in this research. The arrangement of each run of the numerical simulation was: rake angle; cutting edge radius; incidence angle; cutting speed of $600 \mathrm{~m} / \mathrm{min}$; and P10, P15 and P25 inserts.

Table 4 Variables considered in the numerical simulation

\begin{tabular}{ccccc}
\hline Cutting speed $(\mathrm{m} / \mathrm{min})$ & Zone & P10 & P15 & P25 \\
\hline \multirow{2}{*}{600} & Rake angle & A-600.P10 & A-600.2 & A-600.3 \\
& Cutting edge radius & R-600.P10 & R-600.2 & R-600.3 \\
& Incidence angle & I-600.P10 & I-600.2 & I-600.3 \\
\hline
\end{tabular}

The temperature of the cutting tool will be analyzed according to three zones: the zone defined by the rake angle, the zone defined by the cutting edge radius and the zone defined by the incidence angle. Fig. 5 shows the discretization of the cutting tool and its zoning based on the aforementioned criteria. Points from P1 to P20 correspond to the rake angle surface of the cutting tool, points P21 to P28 correspond to the cutting edge radius and from $\mathrm{P} 29$ to $\mathrm{P} 32$ to the incidence angle surface.

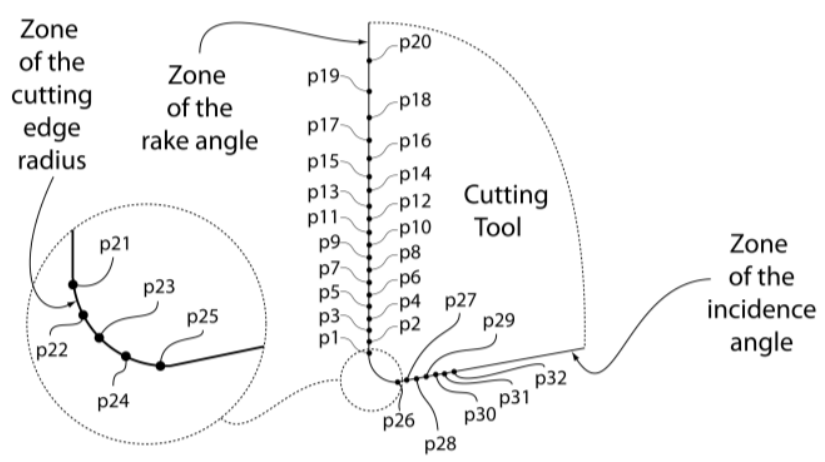

Fig. 5 Discretization of the cutting tool by zones 


\section{RESULTS AND DISCUSSION}

The results related to the finite element simulation of the temperature distribution in the three evaluated cutting tools in the dry high-speed machining of AISI 1045 steel are presented below.

\subsection{Effect of high speed manufacturing and coatings on tool temperature}

Fig. 6 shows the isothermal lines in the Y-Z plane, restricted for clarity to the region closer to the cutting tool zones. Fig. 6 (a) represents the case of no coating (the uncoated cermet CT5015-P10) and perfect contact over the full contact length. Fig. 7(b) represents similar condition, but with a coated carbide tool GC4215-P15. In Fig. 7(c), the tool was a coated carbide tool of type GC4225-P25.

The figure shows that for the same high cutting speed of $600 \mathrm{~m} / \mathrm{min}$, the presence of coating causes the field temperatures to shift from the cutting edge to the other extreme point of the contact length ( $1_{c}$ in Fig. 3), as showed in Figs. 6 (b) and 6 (c). In the case of coated inserts, a similar behavior is observed in terms of temperature distribution, and in their distribution in the contact length. The highest temperature point is reached in practically the same position as the contact length for the three cutting tools studied. For the studied conditions, it indicates that high speed machining does not have a decisive influence on the location of the point of maximum temperature in the contact length.

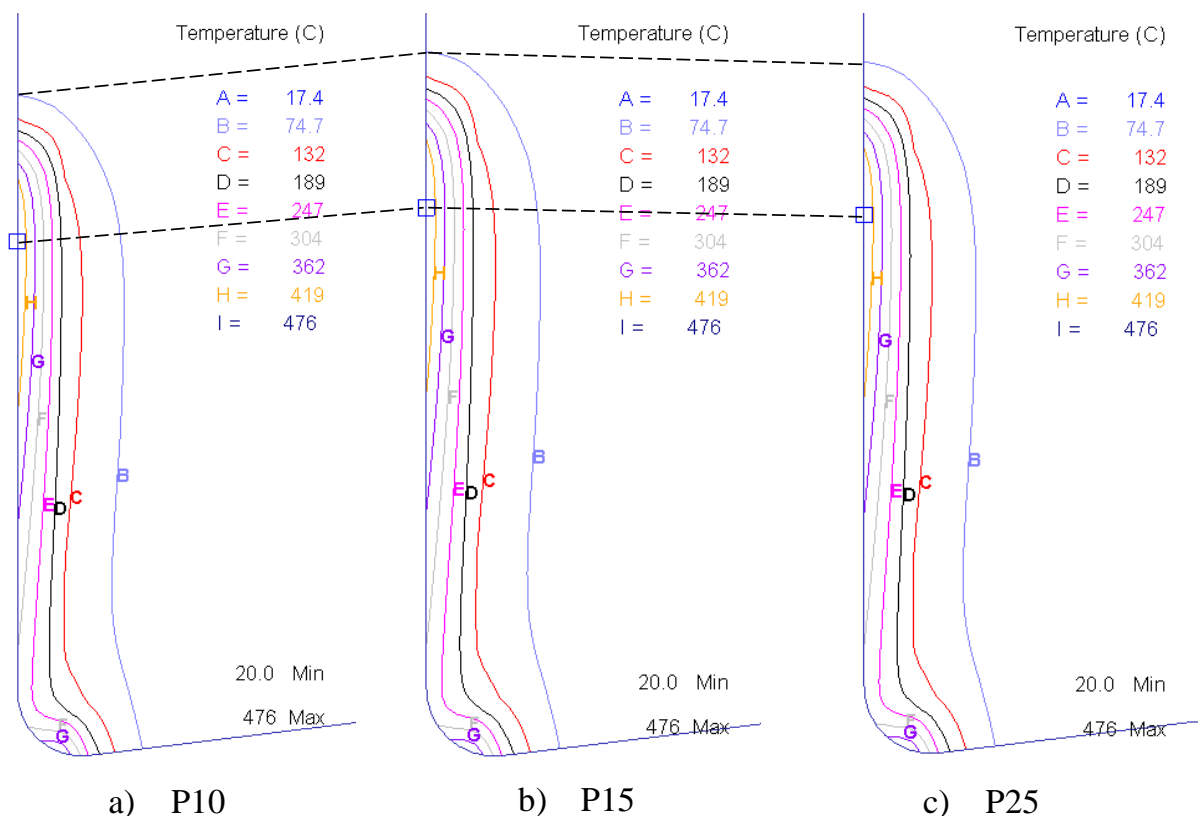

Fig. 6 Effect of high-speed manufacturing and coating on temperature distribution in the tools 


\subsection{Temperature distribution in the considered contact zones}

In order to evaluate the ways in which temperature behaves in the three modeled contact zones, their behaviors are presented below for the three cutting tools under study.

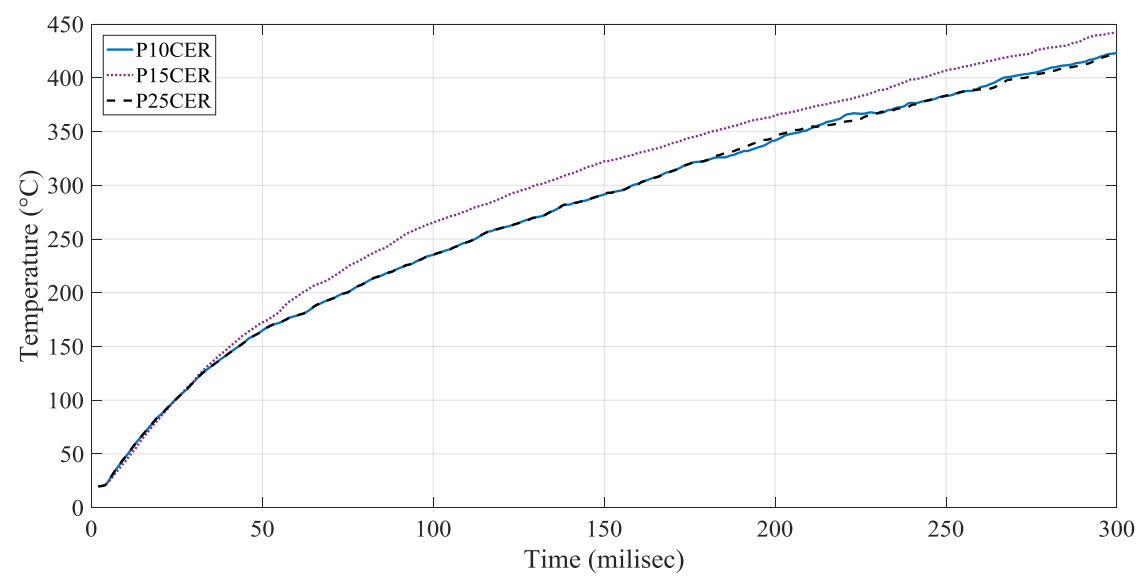

Fig. 7 Behavior of temperature in the zone of the cutting edge radius

Fig. 7 shows the behavior of the temperature in the zone of the cutting edge radius (CER), as a function of time for the three tools. It is observed that in the case of the tool with three coatings (P15), its behavior is slightly superior compared with the other two tools. In general, it is observed that the use of a high cutting speed does not imply an appreciable manifestation of temperature differences in this zone.

Fig. 8 represents the behavior of the temperature in the contact zone of the incidence angle (IA), as a function of time for the three tools. In this case, it can be seen that the tool with three coatings (P15) has the best behavior compared to the other two tools, which are similar.

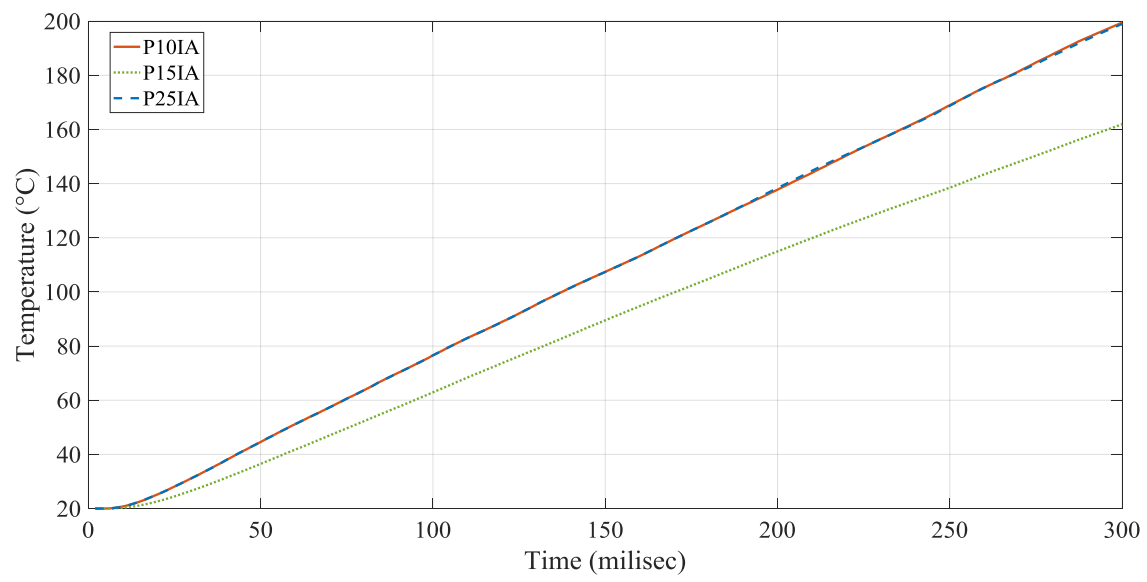

Fig. 8 Behavior of the temperature in the zone of the incidence angle 
The behavior of the temperature distribution in the area of the rake attack surface (RA) is presented in Fig. 9. It shows that the insert with three coatings (P15) heats up slightly more than the other two inserts. Like the aforementioned regarding the cutting edge radius, the difference is not significant.

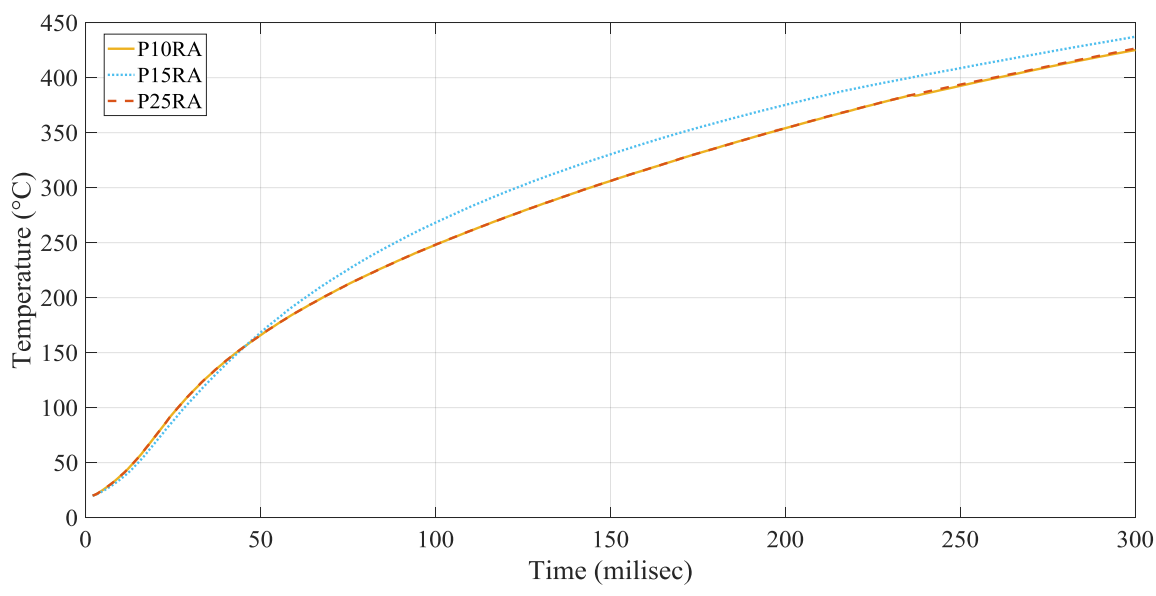

Fig. 9 Behavior of the temperature in the zone of the rake angle

In general, it is observed that the behavior of the three inserts is similar in the case of the rake attack surface and the cutting edge radius but not so in the incidence angle. It is concluded from the thermal point of view that the dry high speed machining in AISI 1045 steel, for the analyzed conditions, does not produce significant changes when varying the inserts analyzed.

\section{CONCLUSION}

This paper presents a comprehensive experimental numerical evaluation of the influence of high cutting speeds on the temperature distribution in different typologies of cutting tools, with the aim of evaluating their behavior on the dry high-speed turning of AISI 1045 steel.

The results indicate that the dry high-speed turning of AISI 1045 steel does not influence significantly the temperature field zones, when we use the P10, P15 or P25 inserts. Therefore, the use of the dry high-speed turning method, which reduces the amount of lubricant and increases productivity, may represent an alternative to turning to the extent here described.

Acknowledgements: The paper is a part of the research done within the project "Experimental study and numerical simulation to improve the performance of cutting tools in high-speed machining on machine tools" of the University of Holguin. The authors would like to thank to the CAD/CAM Study Center at the Engineering Faculty in University of Holguin (Cuba), the Civil Engineering Career at the Faculty of Technical Sciences in the Universidad Estatal del Sur de Manabi (Ecuador), and the Mechanical Engineering Department at the Polytechnic University of Catalonia (Barcelona, Spain) for the support provided. 


\section{REFERENCES}

1. Sulaiman, S., Roshana, A., Ariffin, M.K.A., 2013, Finite element modeling of the effect of tool rake angle on tool temperature and cutting force during high speed machining of AISI 4340 steel, Proc. 2nd International Conference on Mechanical Engineering Research, 1-4 July, Kuantan, Pahang, Malaysia.

2. Özel, T., Altan, T., 2000, Determination of workpiece flow stress and friction at the chip-tool contact for highspeed cutting, International Journal of Machine Tools \& Manufacture, 40, pp. 133-152.

3. Özel, T., Altan, T., 1998, Modeling of high speed machining processes for predicting tool forces, stresses and temperatures using FEM simulations, Proc. of the CIRP International Workshop on Modeling of Machining Operations, Atlanta, Georgia, USA.

4. Usui, E., Takeyama, H., 1960, A photoelastic analysis of machining stresses, Journal Engineering for Industry, 82(4), pp. 303-307.

5. Wallace, P.W., Boothroyd, G., 1964, Tool forces and tool-chip friction in orthogonal machining, Journal of Mechanical Engineering Science, 6(1), pp. 74-87.

6. Karpat, Y., Özel, T., 2006, Predictive analytical and thermal modeling of orthogonal cutting process-Part I: predictions of tool forces, stresses, and temperature distributions, Journal of Manufacturing Science and Engineering, 128, pp. 435-444.

7. Astakhov, V.P., Outeiro, J., 2019, Importance of temperature in metal cutting and its proper measurement/ modeling. In J. Davim (Ed.), Measurement in Machining and Tribology, Springer, Cham, pp. 1-47.

8. Gao, Y., Mann, J.B., Chandraseka, S., Sun, R., Leopold, J., 2015, Heat flux in cutting: importance, simulation and validation, Procedia CIRP, 58, pp. 204-209.

9. Putz, M., Schmidt, G., Semmler, U., Dix, M., Bräunig, M., Brockmann, M., Gierlings, S., 2015, Heat flux in cutting: importance, simulation and validation, Procedia CIRP, 31, pp. 334-339.

10. Attia, M.H., Kops, 1., 2004, A new approach to cutting temperature prediction considering the thermal constriction phenomenon in multi-layer coated tools, CIRP Annals, 53(1), pp. 47-52.

11. Abouridouane, M., Klocke, F., Döbbeler, B., 2016, Analytical temperature prediction for cutting steel, CIRP Annals - Manufacturing Technology, 65, pp. 77-80.

12. Arshinov, V., Alekseev, V., 1973, Metal cutting theory and cutting tool design, Moscow, USSR: Mir.

13. Kus, A., Isik, Y., Cakir, C. M., Coşkun, S., Özdemir, K., 2015, Thermocouple and infrared sensor-based measurement of temperature distribution in metal cutting, Sensors, 15, pp. 1274-1291.

14. Leopold, J., 2014, Approaches for modelling and simulation of metal machining - a critical review, Manufacturing Review, 1, pp. 1-7.

15. Chinchanikar, S., Choudhury, S.K., 2015, Machining of hardened steel-Experimental investigations, performance modeling and cooling techniques: A review, International Journal of Machine Tools and Manufacture, 89, pp. 95-109.

16. Özel, T., Altan, T., 2000, Process simulation using finite element method - prediction of cutting forces, tool stresses and temperatures in high-speed flat end milling, International Journal of Machine Tools \& Manufacture, 40, pp. 713-738.

17. Özel, T., 2003, Modeling of hard part machining: effect of insert edge preparation in CBN cutting tools, Journal of Materials Processing Technology, 141, pp. 284-293.

18. Fang, G., Zeng, P., 2007, FEM investigation for orthogonal cutting process with grooved tools-technical communication, Machining Science and Technology, 11(4), pp. 561-572.

19. Agmell, M., Bushlya, V., M'Saoubi, R., Gutnichenko, O., Zaporozhets, O., Laakso, S., Stahl, J.E., 2020, Investigation of mechanical and thermal loads in $p c B N$ tooling during machining of Inconel 718, International Journal of Advanced Manufacturing Technology, 107, pp. 1451-1462.

20. Al-Zkeri, I., Rech, J., Altan, T., Hamdi, H., Valiorgue, F., 2009, Optimization of the cutting edge geometry of coated carbide tools in dry turning of steels using a finite element analysis, Machining Science and Technology, 13, pp. 36-51.

21. Arrazola, P. J., Özel, T., 2010, Investigations on the effects of friction modeling in finite element simulation of machining, International Journal of Mechanical Sciences, 52, pp. 31-42.

22. Karpat, Y., Özel, T., 2008, Analytical and thermal modeling of high-speed machining with chamfered tools, Journal of Manufacturing Science and Engineering, 130(1), pp. 1-15.

23. Özel, T., Altan, T., 2005, Finite element modeling of stresses induced by high speed machining with round edge cutting tools, Proc. of ASME International Mechanical Engineering Congress \& Exposition, Orlando, Florida, USA.

24. Özel, T., Llanos, I., Soriano, J., Arrazola, P.J., 2011, 3D finite element modelling of chip formation process for machining inconel 718: comparison of FE software predictions, Machining Science and Technology, 15, pp. 21-46. 
Finite Element Modeling of Temperature Felds on the Cutting Edge in the Dry High-Speed Turning... 217

25. Tang, L., Huang, J., Xie, L., 2011, Finite element modeling and simulation in dry hard orthogonal cutting AISI D2 tool steel with CBN cutting tool, International Journal of Advanced Manufacturing Technology, 53, pp. 1167-1181.

26. Ucun I, Aslantas K., 2011, Numerical simulation of orthogonal machining process using multilayer and singlelayer coated tools, International Journal of Advanced Manufacturing Technology, 54, pp. 899-910.

27. Yun-Song, L., Chen-Liang, M., Ming, L., Hui-Feng, C., Bin, Y., 2019, Three-dimensional numerical simulation of soft/hard composite-coated textured tools in dry turning of AISI 1045 steel, Advances in Manufacturing, 7, pp. 133-141.

28. Akbar, F., Mativenga, P.T., Sheikh, M. A., 2008, An evaluation of heat partition in the high-speed turning of AISI/SAE 4140 steel with uncoated and TiN-coated tools, Proc. of the Institution of Mechanical Engineers, Part B: Journal of Engineering Manufacture, 222(7), pp. 759-771.

29. Akbar, F., Mativenga, P. T., Sheikh, M.A., 2010, An experimental and coupled thermo-mechanical finite element study of heat partition effects in machining, International Journal of Advanced Manufacturing Technology, 46, pp. 491-507.

30. Heisel, U., Storchak, M., Krivoruchko, D., 2013, Thermal effects in orthogonal cutting, Production Engineering: Research and Development, 7, pp. 203-211.

31. Hernández-González, L.W., Seid-Ahmed, Y., Pérez-Rodríguez, R., Zambrano-Robledo, P.C., Guerrero-Mata, M.P., 2018, Selection of machining parameters using a correlative study of cutting tool wear in High-Speed Turning of AISI 1045 steel, Journal of Manufacturing and Materials Processing, 2(4), 66, doi: 10.3390/ jmmp2040066 